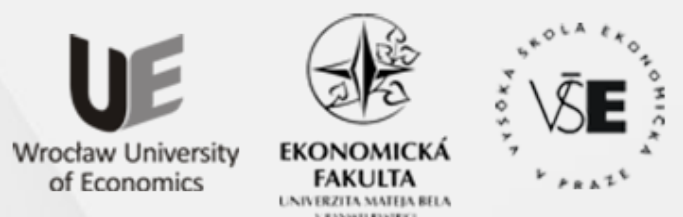

Conference Proceedings

Full TeXT PAPERS

edited by

Zofia Rusnak and Beata Zmyślona

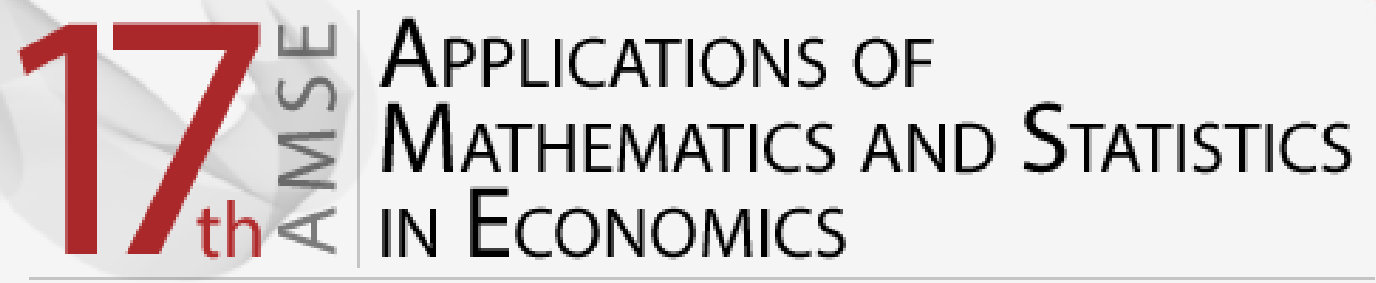

International Scientific Conference | Poland • 27-31 August 2014 
Scientific Committee

Richard Hindls, Stanislava Hronová, Rudolf Zimka, Walenty Ostasiewicz, Emília Zimková, Zofia Rusnak, Martin Bod'a

Organizing Committee

Beata Zmyślona, Cyprian Kozyra, Grzegorz Rogoziński, Kristýna Vltavská

\section{Reviewers}

Milan Bašta, Diana Bílková, Martin Bod'a, Joanna Dębicka, Tomáš Fiala, Jakub Fischer, Stanisław Heilpern, Karel Helman, Lenka Hudrlíková, Miroslav Hužvár, Nikola Kaspř́ková, Alena Kaščáková, Kamil Kladívko, Jindřich Klůfa, Pavol Král', Katarzyna Kuziak, Jana Langhamrová, Ivana Malá, Tomáš Marcinko, Luboš Marek, Miloš Maryška, Petr Mazouch, Zofia Mielecka-Kubień, Witold Miszczak, Petr Musil, Gabriela Nedelová, Walenty Ostasiewicz, Iva Pecáková, Viera Roháčová, Zofia Rusnak, Mária Stachová, Jana Špirková, Šárka Šustová, Jana Tepperová, Vladimír Úradníček, Kristýna Vltavská, Michal Vrabec, Dariusz Wawrzyniak, Henryk Zawadzki, Jaroslav Zbranek, Tomáš Zeithamer, Martin Zelený, Jan Zeman, Rudolf Zimka, Emília Zimková, Pavel Zimmermann, David Žižka

Layout

Martin Bod'a, Beata Zmyślona, Grzegorz Rogoziński

Front page design

Grzegorz Rogoziński

CD cover design

Beata Dębska

Articles published in the form submitted by the authors

All rights reserved. No part of this book may be reproduced in any form or in any means without the prior permission in writing of the Publisher

(C) Copyright by Wrocław University of Economics Wrocław 2014

ISBN 978-83-7695-421-9

Wydawnictwo Uniwersytetu Ekonomicznego we Wrocławiu

53-345 Wrocław, ul. Komandorska 118/120 www.ue.wroc.pl

Sprzedaż książek tel./fax 71 36-80-602

e-mail: econbook@ue.wroc.pl www.ksiegarnia.ue.wroc.pl 


\section{Contents}

Foreword

Diana Bílková: TL-Moments: Analogy of Classical L-Moments

Dagmar Blatná: Application of Robust Regression in the Analysis of Internet Access in European Countries

Martin Bod’a, Mária Kanderová: Rebalancing Issues in Tracking Error Variance Minimization

Martin Bod'a, Viera Roháčová: Application of Six Sigma Ideas to Timing Decisions at Financial Markets

Anton Dekrét, Rudolf Zimka: On the Price Hartwick's Task and Its Inverse in a Dynamic Model of an Economy with Exhaustible Resources

Joanna Dębicka, Agnieszka Marciniuk: Comparison of Reverse Annuity Contract and Reverse Mortgage on the Polish Market.

Petra Dotlačilová, Jitka Langhamrová: The Influence of Mortality Models for the Expected Future Life-time of Older People

Marek Ďurica, Lucia Švábová: Delta and Gamma for Chooser Options.

Vlastimil Farkašovský: New Concept of Pension Funds Performance Evaluation

Albert Gardon: The Normality of Weekly Relative Changes of the Freight Rate in Container Shipping.

Mária Grausová, Miroslav Hužvár, Jana Štrangfeldová: Healthcare Systems Efficiency in the Visegrád Group.

Stanisław Heilpern: Multiple Life Insurance - Pension Calculation

Alena Kaščáková, Gabriela Nedelová: Changes in Slovak Households' Economy

Igor Kollár, Pavol Král', Peter Laco: Methodology for Assessing Website Improvement in Corporate Environment.

Maciej Kostrzewski: Some Method of Detecting the Jump Clustering Phenomenon in Financial Time Series.

Cyprian Kozyra, Beata Zmyślona, Katarzyna Madziarska: Complementary Objective and Subjective Measures of Hospital Services Quality...

Pavol Král', Mária Stachová, Lukáš Sobíšek: Utilization of Repeatedly Measured Financial Ratios in Corporate Financial Distress Prediction in Slovakia

Ivana Malá: The Use of Finite Mixture Model for Describing Differences in Unemployment Duration

Lukáš Malec: Studying Economics and Tourism Industry Relations by Smooth Partial Least Squares Method Depending on Parameter. 
Tomáš Marcinko: Consequences of Assumption Violations Regarding Classical Location Tests.

Edyta Mazurek: The Income Tax Progression Depending on Social Insurance Contribution in Poland.

Petr Musil, Jana Kramulová, Jan Zeman: Regional Consumption Expenditures: An Important Starting Point for Regional Input-output Tables.

Katarzyna Ostasiewicz, Walenty Ostasiewicz: Good Life: From Political to Human Economy

Anna Sączewska-Piotrowska: Analysis of Poverty Transitions in Poland Using Multilevel Discrete-Time Event History Models

Martina Šimková, Petra Švarcová: Disadvantaged University Students in the Czech Republic.

Michal Široký: The Use of Short-term Business Statistics for Quarterly GDP Flash Estimates in the Czech Republic

Zdeněk Šulc, Hana Řezanková: Evaluation of Recent Similarity Measures for Categorical Data.

Lucia Švábová, Marek Ďurica: The Relationship Between the Finite Difference Method and Trinomial Trees

Kristýna Vltavská, Jaroslav Sixta: The Estimation of Final Consumption Expenditures

Lenka Vraná: Business Cycle Analysis: Tracking Turning Points

Janusz Wywiał: On Bayesian Testing in Auditing

Emília Zimková: Window Analysis of Supper-efficiency Change: Case of the Slovak Banking System ....

Beata Zmyślona: Statistical Modelling of the Impact of Diabetes on the Risk of Hospitalization 


\title{
METHODOLOGY FOR ASSESSING WEBSITE IMPROVEMENT IN CORPORATE ENVIRONMENT
}

\author{
IGOR KOLLÁR, PAVOL KRÁl, PETER LACO \\ Matej Bel University in Banská Bystrica, Faculty of Economics, \\ Department of Quantitative Methods and Information Systems, \\ Tajovského 10, Banská Bystrica, Slovakia \\ email: igor.kollar@umb.sk,pavol.kral@umb.sk, peter.laco@umb.sk
}

\begin{abstract}
The Internet is the most common channel of communication for businesses today and companies' websites play an important role in promoting and selling services and products to customers, to communicate with business partners and government institutions. Therefore, if we would like to increase efficiency of communication in an adopted business model, improvement of a corporate website is often necessary. The main goal of the paper is to propose a simple methodology how to asses such a website improvement in corporate environment. We identify here the most important criteria for evaluation of websites, classify them as quantitative and qualitative and propose a simple way how to quantify the overall improvement of a website of interest. Moreover, we created a simple evaluation tool based on the proposed methodology and we published it on a public accessible website. For illustration purposes, the proposed methodology is applied to the website of Faculty of Economics, Matej Bel University and functionality of the tool is presented.
\end{abstract}

Key words: internet, website improvement, measuring, evaluation, corporation.

DOI: $10.15611 /$ amse.2014.17.14

\section{Introduction}

The Internet is the most common channel of communication for businesses today. Corporations use the Internet to promote and sell their products and services to customers using e-commerce solutions (standard model B2C - Business to Customer), to communicate with business partners (B2B - Business to Business), to communicate with government institutions (B2G - Business to Government) and others (C2C - Customer to Customer, C2B - Customer to Business etc.). Regardless the adopted business model the impact of the modern information and communication technologies and the importance of the e-commerce solutions is indisputable (Šperka, Slaninová, 2012). The most common way for corporations to present information about their products and services for current or potential customers, as well as basic information about themselves is formed by websites. The concept of websites is also utilized in intranet solutions to support information and knowledge sharing among employees of a company. Tim Berners-Lee proposed the concept of the web in 1989. It was a system based on three main ideas: hypertext navigation, multimedia support, and integration of existing Internet services. The usage of the web on the Internet began in 1991 and caused its enormous growth. Since then the number of Internet users doubles every year. Successful website presentation on the Internet and/or intranet solution and its continuous improvement are thus inevitable for corporations to be successful in today's global information society. The 
aim of the paper is to propose a simple methodology how to assess such a website improvement in corporate environment with focus on small and medium enterprises hosting their websites using enterprise hosting services. The proposed methodology can be interesting for decision makers in corporate environment, e.g. company managers, owners, shareholders, etc., because it allows them to identify shortcoming in current communication of the company and to measure results of their effort to improve it.

In our context, the website is understood as group of webpages that create a presentation of a specific company or product. These webpages are connected by hypertext links, i.e. the highlighted words, phrases, images or animations referring to another webpage on the same website. Web pages are created in HTML (Hyper-Text Markup Language), a code that defines the way the content is displayed in the browser. Websites are published on the webservers and the transfer to client (visitor) computer over the Internet is based on HTTP (Hyper-Text Transfer Protocol) or its secured version HTTPS. and propose a simple way how to quantify the overall improvement of a website of interest. Moreover, we created a simple evaluation tool based on the proposed methodology and we published it on a public accessible website. For illustration purposes, the proposed methodology is applied to the website of Faculty of Economics, Matej Bel University and functionality of the tool is presented.

The paper comprises five main parts. First, we identify the most important criteria for evaluation of websites using visitors of webpage of Faculty of Economics, Matej Bel University. Second, we classify them as quantitative and qualitative. Third, we discuss the possibilities of measuring the level of their improvement. Forth, we propose a simple evaluation of the overall improvement of a website of interest. We also provide reader with some recommendations how to achieve immediate and direct website improvement in corporate environment. Finally, we apply our methodology to the website of Faculty of Economics, Matej Bel University. Moreover, we created tool for website improvement evaluation and we illustrate here its functionality.

\section{Survey based identification of criteria for assessing websites}

There are many methodologies available for website evaluation but most of them are aimed at technical issues (Page Ranking, Search Engine Optimization) or on Google Analytics (Pageviews, Visits, Bounce Rate, Goals conversion). Contrary, we focus on website visitors' point of view. Following known results described in (Alva et al., 2003), (Leporini, Paterno, 2003) and (Krug, 2006) we identified the list of criteria, which can be considered as the most important for website visitors. Although all criteria proved to be important for the websites visitors in general, we recommend to realize a corporate specific survey to gain information about target website visitors' preferences. As an example, we realized the survey of Faculty of Economics, Matej Bel University visitors' preferences.

The survey was realized during the years 2006-2012 and number of respondents exceeds 350. Respondents were mainly young people under 25 who have completed at least secondary school, both men and women. More detailed socio-economic characteristics of the respondents have not been investigated. In the final evaluation only answers to the questions that have been observed during the whole investigated period were included. Respondents evaluated the individual criteria of the web pages in general, irrespective of the nature of business. They rated the importance of each criterion from 1 (the least important) to 5 (the most important). The aim of the survey was not to find out what is the opinion of respondents on specific websites, but to identify the preferences of website visitors. Since 2011, the 
questionnaire was processed using the online forms, using technology docs.google.com, set of tools that are available to everyone for free. The yearly numbers of respondents who filled out the questionnaire are listed in the following table.

Table 1. Number of respondents during the period 2006-2012.

\begin{tabular}{cc}
\hline Year & Number of respondents \\
\hline 2012 & 151 \\
2011 & 50 \\
2009 & 35 \\
2008 & 9 \\
2007 & 90 \\
2006 & 36 \\
\hline Total & 371 \\
\hline
\end{tabular}

Source: Own data.

IBM SPSS Statistics software was used to process the observed data. Mean Ranks (from Friedman test) representing importance of individual preferences are summarized in the following table.

Table 2. Preferences of respondents.

\begin{tabular}{ccc}
\hline Order & Preferences & Mean Rank \\
\hline 1 & Up-to-date content & 9,17 \\
& Security & 9,00 \\
& Functionality of all pages and its parts & 8,90 \\
\hline 2 & Intuitive - simple navigation & 8,71 \\
& Content & 8,64 \\
& Speed & 8,31 \\
\hline 3 & Disturbing advertisements & 6,62 \\
\hline 4 & Simple and easy to remember address, searchable via search engines & 6,54 \\
\hline 5 & Design, originality & 5,97 \\
\hline 6 & Correct view at various screen resolutions & 5,96 \\
\hline 7 & Site search & 4,69 \\
\hline 8 & Interactivity - feedback forms, forums & 4,31 \\
& Language versions & 4,17 \\
\hline
\end{tabular}

Source: Own data.

Differences in preferences of visitors were tested using Wilcoxon signed rank tests (see Hollander et al., 2014 for details). The first three preferences: "Up-to-date content, Security, Functionality of all pages and its parts" are the most important for respondents. The differences between these preferences for the users were so small that we consider it insufficient to rank them. Similarly, the other three preferences: "Intuitive - simple navigation, Content, Speed" form group in the second place. Other individual preferences follows and the last two: "Interactivity and Language versions" seems to be indistinguishable too because the corresponding differences in the preferences were not statistically significant. Data 
indicates that preferences of visitors remained stable in all years but the stability of preferences during the years was not verified by statistical testing.

\section{Classification of web quality criteria and their quantification}

It is obvious that quantification of identified preferences of websites' users is context dependent. Therefore metrics for website improvement evaluation presented in this section have limitations and can be further modified and tailored. We can divide all criteria from the above mentioned survey roughly into three groups. The first group consists of quite easily measurable criteria. The second one includes criteria where it is necessary to capture the opinion of web page visitors about perceived improvement via surveys. The third group is formed by criteria unsuitable for small and medium enterprises we are focusing on. Let us discuss individual criteria listed in Table 1 in more details.

Up-to-date content $(\mathrm{u})$ belongs to the first group and can be measured as ratio of up-to-date pages on the total number of pages. Up-to-date content we define as valid content, e.g. content which is correct and still relevant at the given time point, e.g. price list for the year 2013 is still correct but not relevant in the year 2014. For simplicity, we assume here that a new webpage is up-to-date. If $98 \%$ or more pages are up-to date we are fully satisfied. On the other hand if up-to-date pages form less than $90 \%$ of pages we are completely unsatisfied. The quantification can be done by user or by software tools. Software tools are much faster than individual users, but have some limitations. Individual users are better for small websites because they are able to check also the content of the site. In case of big website it is better to use software tools with a possibility to set a date of expire for each webpage individually.

Security is a very complex issue, in general we can state, that its quantification depends on amount and importance of services provided by the website. Security is more significant for websites providing some special services, e.g. online payments, website visitor registration, mailing lists registration. It can be quantified as a number of security incidents during certain period of time (se), for example during a one year in case of annual website improvement measurement. Of course it is necessary to take into account also the character of security incidents, i.e. we need to distinguish between minor issues and critical errors. As was already mentioned in Introduction, we focus on small and medium enterprises without own webservers. In that case the security issues are directly connected to external web service providers. Therefore this criterion belongs to the third group of criteria and we omit it in our further analysis.

Level of functionality can be expressed relatively easily - as a number of errors, e.g. broken links, missing pictures, missing subpages etc., on the website and its parts (f). It can be again quantified by user, but software tools, like Google Analytics, are also available. We recommend using software tools, because there is possibility to check each error individually and also view history of errors during specified time period. If $0,1 \%$ of elements or less are incorrect we can be fully satisfied, more than $1 \%$ of broken, missing etc. elements are unacceptable.

Intuitive and simple navigation belongs to the second group of website visitors' preferences. It can be quantified by the survey, called eye - tracking $(\mathrm{N})$. Also a simple test of navigation can be used (Krug, 2006). For each page of a website you should be able to answer following questions:

- What is the name of the website (logo)?

- What is the name of the webpage (page title)? 
- What are the main navigation sections?

- What can I do at this navigation level?

- Where I am in the website hierarchy?

- How can I search?

If you can answer all the questions, your navigation is good.

Content (c) is another criterion belonging to the second group where a survey among website visitors is recommended. To gain a feedback from webpage visitors, a feedback form for each webpage can be used. Content should be easy to understand to website audience.

In contrast, speed (t) can be relatively easy quantified using software tools like Google Analytics, WebPagetest or others. An optimal webpage load time has to be three seconds or less. If the load time is higher, there is a big risk of losing returning visitors. Ratio of mobile visitors using smartphones is rising, but the speed of mobile internet connection is lower compared to speed of "classic" internet connection. Because of this, mobile visitors should be measured individually. Mobile web users are willing to wait longer than desktop users for a site to be loaded. We recommend to create a separate mobile version of the website. To get an average page load time the simple average or the weighted average can be used. For PC (mobile) visitors 3 (10) seconds or less are fully satisfactory, 7 (20) seconds and more are unacceptable, respectively. The third important metric, a number of disturbing advertisements (a) depends on a website owner decision and we omit it.

A web address of the website, also called domain, depends mainly on a website owner decision (if the domain is freely available). Although the fact whether it is simple and easy to remember can be again answered by a survey, we prefer to put this criterion into the third group. Our main reason is that often there is not much space left for improvements.

Every published website is searchable via search engines, but the way how to get on the top of the searches for specific keywords is called Search Engine Optimization (SEO). Quantification of this metric can be the position in web search results for specific keyword or by Google PageRank (si). Google PageRank can be checked by one of many free online Google PageRank tools (http://checkpagerank.net/, http://www.page-rank.sk/).

Value 8 or more is seen as an ideal one, value less than 4 is unsatisfactory. Another possibility how to evaluate this criterion is Keyword Ranking, it means position of a website in search engine results for a specific keyword. There are more tools available to help you evaluate position of you website, e.g. SEO Centro Rank Checker (http://www.seocentro.com/tools/search-engines/keyword-position.html), Small SEO Tools Keyword Position Tool (http://smallseotools.com/keyword-position), SERPs Free Keyword Rank Checker \& SERP Checker (https://serps.com/tools/rank_checker). All of these tools evaluate position in Google, Bing and Yahoo!. In this case position from 1 to 3 are seen as the best, position 15 or higher as the worst possibility. Because of different popularity of search engines, we decided to set directly the following weights for each of them: Google $(0.65)$, Bing (0.2), Yahoo! (0.15). For each website we can use more keywords. In that case, we can also add the weights of each keyword representing the importance of the keyword.

Design and originality (d) belong to the second group. A correct view at various screen resolutions can be determined only by testing. To set optimal screen resolution, global web statistic or Google Analytics results can be used (Sc).

Existence of a Site search (S) depends on our decision, free tools like Google Custom Search (earlier known as Google Site Search) are available. It is possible to develop own search, but it is difficult, costly and potentially dangerous due to security issues, especially 
SQL Injection. Functionality of a Site search can be tested for the most important keywords on a website and quantified with respect to obtained results.

Interactivity - feedback forms, forums are dynamic parts of the website that are on the one hand interesting and useful for the website visitors, on the other hand dangerous due to mentioned security issues (SQL Injection). Quantification could include in addition to the number of interactive elements also the number of posts in forums or received messages via a web based feedback form (i). It is not possible to set a universal interactivity specification, because different business fields and different target groups require specific interactivity levels. Because of the different importance for different business fields, we recommend to use a survey aimed on website visitors`expectations.

A number of language versions (l) is clear and easily measurable. It can be straightforwardly improved using support of tools like Google Translate. The use of automated translation is risky, because some of the terms can be translated incorrectly and cannot be corrected manually. The decision which languages to support can be based on corporate strategy, but also on analysis of website visitors countries for example by Google Analytics. Of course, not only the number of language versions is important, but also up-todate content of all language webpage mutations. Obviously we prefer less language versions with up-to-date content to more language versions with old content. To evaluate this criterion we suggest to compare available language versions with target markets. Weight for each market should be set based on importance of this market for the company.

\section{Assessing of website improvement}

We already discussed criteria of web quality and possibilities of their measurements. As our aim is to propose an easily applicable methodology for assessing website improvement in a corporate environment resulting to easily interpretable results, we need to specify the way how to summarize measurements of individual criteria that are very different to each other. Because of the nature of variables we propose to summarize the first and the second group of criteria separately. Metrics proposed for quantification of criteria from the first group can take continuous or discrete values, i.e. they can be seen as discrete or continuous variables. On the other hand, quantification of criteria included in the second group leads to ordinal variables.

Let us start with the first group. In this case we transform ranges of all proposed metrics to the unit interval, when 1 is assigned to values of a metric representing satisfactory performance and 0 is assigned to values of a metric representing unsatisfactory performance of our webpage with respect to a selected criterion. The rest of possible values we transform using a monotone function. For the sake of simplicity, in our paper we restrict ourselves to linear functions. Let $m$ be a cardinality of the first group, i.e. the number of criteria included in the first group. Overall quality of our webpage with respect to the first group of criteria can be then represented as a point in an $m$-dimensional hypercube, where each coordinate is a number from the unit interval. Analogously, quality of an ideal web page is represented as a point of $m$-dimensional hypercube where each coordinate is the number 1 . Potential for web page improvement (QIP) then can be naturally quantified as a distance between these two points. We can use Euclidean distance to measure the distance between points in that case. (see Equation (1)).

$$
\operatorname{QIP}(w p)=\sqrt{\left(1-x_{1}(w p)\right)^{2}+\left(1-x_{2}(w p)\right)^{2}+\cdots+\left(1-x_{d-1}(w p)\right)^{2}+\left(1-x_{d}(w p)\right)^{2}},
$$


where $w p$ denotes a web page, $x_{i}(w p)$ denotes a transformed measurement of $\mathrm{i}^{\text {th }}$ criterion for the web page $w p$.

The web page after improvement represents a new point of hypercube and the achieved improvement can be seen as a difference D of distances between each of these two points and the point representing an ideal webpage (see Equation (2)).

$$
\mathrm{D}(\text { new } w p, \text { old } w p)=\operatorname{QIP}(\text { new } w p)-\operatorname{QIP}(\text { old } w p),
$$

where $x_{i}$ is a transformed value of $\mathrm{i}^{\text {th }}$ criterion.

For the second group we can use very similar idea, but in this case ranges of variables correspond to ordinal scale. We think that a very simple scale consisting of three levels $(0-$ major improvement is necessary, 1 - minor improvement is necessary, 2 - no improvement is necessary) is sufficient in our case. Because criteria are quantified using the ordinal scale we decided to modify the above mentioned approach in order to avoid improper interpretation of results. Let $n$ be a cardinality of the second group, i.e. the number of criteria included in the second group. Analogously to the previous case, we can represent a webpage as a point of $n$ dimensional hypercube where each coordinate is a level of our ordinal scale $(0,1,2)$. For computation simplicity we transform the levels of the scale to $0,0.5,1$. It allows us to use Equation (1) directly. Contrary to the previous case, an ordinal scale and selected criteria provide us only with finite number of webpage states representations. Assuming five criteria and three levels for each there are 243 possible states of our webpage with respect to improvement $((0,0,0,0,0),(0.5,0,0,0,0), \ldots,(1,1,1,1,1)$. Therefore it is quite easy to rank them according to the distance to the ideal point and use the resulting ranking to express possible improvements. The complete procedure is the following.

In the first step we compute Euclidean distance between each possible point representation of our webpage and the ideal point using Equation (1). Some of them are the same. For example, assuming equal weights of criteria we are not able to distinguish between webpages represented by $(1,0,0,0,0)$ and $(0,0,0,0,1)$, respectively. In the second step we omit repeated distances and we apply ascending order to the resulting list of distances. In the third step we identify a position of the distance corresponding to measured representation of our webpage in the constructed ranking. After our attempt to improve the webpage, we repeat the third step once again. Then the difference between ranks before and after our attempt to improve a webpage represents achieved improvement.

In both cases it is possible to incorporate weights to our computation. The higher importance of specific metric (criteria) for the website visitor means higher weight. These weights might change during the time. For simplicity we recommend to start with weights based on the well-known pairwise comparison.

The proposed methodology was implemented using VBA in Microsoft Excel and the created evaluation tool is available at http://1drv.ms/1q6VFrg. The implementation allows user to evaluate each criterion specified above. To measure improvement of criteria in both groups, it is necessary to specify initial value for each criterion. In both cases our program in Microsoft Excel produces potential for improvement for our original and improved webpage as well as assessment of achieved improvement. We can setup range of values for each criterion and the corresponding importance. If importance of criteria is not specified, we assume equal weights for all of them, otherwise weights are computed using a pairwisecomparison. 


\section{Case Study}

Functionality of our tool is illustrated on a case study using website of Faculty of Economics, Matej Bel University in Banská Bystrica (http://www.ef.umb.sk).

First, we set importance for each criterion based on website users' preferences specified in Table 2. The most important criteria are Up-to-date Content and Functionality of all web pages, less important is Number of language versions (see Figure 1).

Subsequently we specified value for each criterion using different techniques and tools. Up-to-date content was verified manually. We checked up content of all webpages. This technique takes a lot of time, but it was the best possibility how to evaluate Up-to-date content. Total number of webpages on the website was 4446 and 447 of them was with Outof-date content. Most of Out-of-date content webpages (421) was in English language version. Based on this survey we can say that ratio of Up-to-date content was $89.95 \%$. After improvement ratio of Up-to-date content was $91.04 \%$.

Functionality of all webpages was evaluated using Xenu's Link Sleuth 1.3.8. We detected totally 26 wrong links on 21 webpages. No missing files or web components was detected. The ration of wrong elements on website was $0.47 \%$. After improvement ratio of nonfunctional webpages was $0.1 \%$.

Website speed was tested using 3 different tools because of different test method and different test server locations. For website speed test is distance between webserver and test server very important. We recommend using website speed test servers placed close to potential website visitors. We tested website speed using test servers located in Europe. Website load time results using different test tools are presented in Table 3. We used median to set website load time before and after improvement.

Table 3. Website loading time using different tools with different test server locations.

\begin{tabular}{|c|c|c|c|}
\hline Tool & $\begin{array}{c}\text { Test server } \\
\text { location }\end{array}$ & $\begin{array}{c}\text { Before } \\
\text { improvement }\end{array}$ & $\begin{array}{c}\text { After } \\
\text { improvement }\end{array}$ \\
\hline $\begin{array}{l}\text { Pingdom Website Speed Test } \\
\text { (http://tools.pingdom.com/fpt/) }\end{array}$ & Amsterdam & $1.8 \mathrm{~s}$ & $1.3 \mathrm{~s}$ \\
\hline $\begin{array}{l}\text { Dotcom-monitor } \\
\text { (http://www.dotcom-monitor.com/WebTools) }\end{array}$ & $\begin{array}{c}\text { Paris } \\
\text { London } \\
\text { Frankfurt } \\
\text { Amsterdam }\end{array}$ & $\begin{array}{l}3.5 \mathrm{~s} \\
3.3 \mathrm{~s} \\
4.0 \mathrm{~s} \\
4.3 \mathrm{~s}\end{array}$ & $\begin{array}{l}3.2 \mathrm{~s} \\
2.9 \mathrm{~s} \\
2.7 \mathrm{~s} \\
3.9 \mathrm{~s}\end{array}$ \\
\hline $\begin{array}{l}\text { WEBPAGETEST } \\
\text { (http://www.webpagetest.org/) }\end{array}$ & $\begin{array}{c}\text { Amsterdam } \\
\text { Dublin } \\
\text { Vianen } \\
\text { Vienna } \\
\text { Falkenstein } \\
\end{array}$ & $\begin{array}{l}5.6 \mathrm{~s} \\
4.3 \mathrm{~s} \\
5.5 \mathrm{~s} \\
7.5 \mathrm{~s} \\
5.0 \mathrm{~s} \\
\end{array}$ & $\begin{array}{l}5.1 \mathrm{~s} \\
3.8 \mathrm{~s} \\
5.1 \mathrm{~s} \\
7.0 \mathrm{~s} \\
4.5 \mathrm{~s} \\
\end{array}$ \\
\hline Median & - & $4.3 \mathrm{~s}$ & $3.85 \mathrm{~s}$ \\
\hline
\end{tabular}

Source: Own data based on results from Pingdom Website Speed Test, Dotcom-monitor and WEBPAGETEST.

To evaluate criterion Searchable via search engines, we used more online Google PageRank tools. All the tools set value of Google PageRank to 6. In spite of some modifications of tested website, Google PageRank remains unchanged. 


\section{APPLICATIONS OF

Faculty of Economics website is available in Slovak and English language version. According to the target market - students from Slovakia and Erasmus students from Europe, we consider the selected number of language versions as sufficient.

Correct view at various screens was tested using online tools Screenfly (http://quirktools.com/screenfly/) and Screen resolution simulator (http://www.infobyip.com/testwebsiteresolution.php). Website displays correct at all tested resolution from 1020 × 768 to 1920 x 1200 .

We set previous state and current state values for each criterion to our tool. Based on this, we calculated website quality before improvement, after improvement and, finally, the improvement (see Figure 1). Website quality was $75.10 \%$ before improvement. After improvement website quality was $81.50 \%$. As you can see, total website quality improvement is $6.40 \%$.

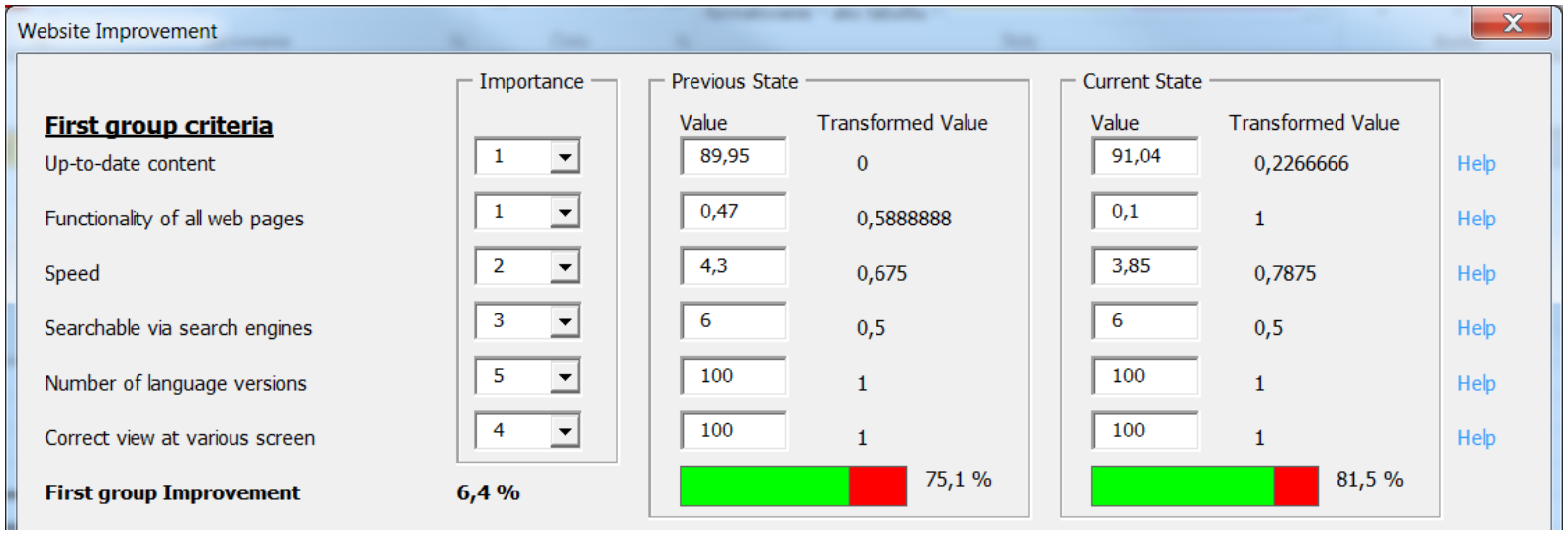

Figure 1 Faculty of Economics website's improvement evaluation Source: Own tool.

\section{Conclusion}

The main contribution of our paper consists of a simple methodology for website improvement measurement. Our proposal is based on the quantification of identified webpage criteria. We classified the criteria into three groups. The first group consists of relatively easy measurable criteria: Up-to-date content, Functionality, Speed, Searchable via search engines, Number of language versions, Correct view at various screen resolutions. The second one includes criteria where it is necessary to capture the opinion of web page visitors about improvement via surveys: Intuitive - Simple navigation, Content, Design and originality, Site search, Interactivity. We also explained the meaning of the third group that is formed by criteria unsuitable for small and medium enterprises we are focusing on: Security, Web address, Disturbing advertisements.

The proposed methodology can be applied to other elements of information systems in corporate environment too. We also presented here partial recommendations how to improve the quality of websites in corporate environment. Such improvement can lead to increased efficiency in a scare resources use, at least at the level of companies. 


\section{Acknowledgements}

The research was supported by KEGA grant agency, grant number 014UMB-4/2012.

\section{References}

1. AlVA, M., MARTineZ, A., CUEVA, J. 2003. Comparison of methods and existing tools for the measurement of usability in the web. In Web Engineering ICWE 2003, pp. 386-389. ISSN 0302-9743

2. HOLlANDER, M., WOLFE, D. A., CHICKEN, E. 2014. Nonparametric Statistical Methods. Wiley. 2014 ISBN 78-0-470-38737-5

3. JOHNSON, J. 2010. Designing with the Mind in Mind. Elsevier - Morgan Kaufmann Publishers, Burlington, USA. 2010. ISBN 978-0-12-375030-3

4. KRUG, S. 2006. Don't Make Me Think! A Common Sense Approach to Web Usability, Second Edition. New Riders Publishing Berkeley, California USA. 2006. ISBN 0-32134475-8

5. LEPORINI, B., PATERNO, F. 2003. Criteria for usability of accessible web sites. In Universal Access: Theoretical Perspectives, Practice, And Experience. 2003, pp. 43-55. ISSN: 0302-9743

6. PALMER, JW. 2002. Web site usability, design, and performance metrics. In Information Systems Research. 2002, pp. 151-167. ISSN: 1047-7047

7. ŠPERKA, R., SLANINOVÁ, K. 2012. The Usability of Agent-Based Simulation in Decision Support System of E-Commerce Architecture. International Journal of Information Engineering and Electronic Business (IJIEEB), vol. 4, no.1, pp.10-17, 2012, Hong Kong, Print ISSN 2074-9023, Online ISSN 2074-9031. Available from: <http://www.mecs-press.org/ijieeb/ijieeb-v4-n1/IJIEEB-V4-N1-2.pdf>.

8. TEZZA, R., BORNIA, A., DE ANDRADE, D. 2011. Measuring web usability using item response theory: Principles, features and opportunities. In Interacting With Computers 2011, pp. 167-175. ISSN: 0953-5438 